\title{
Corrosion Behavior of the S136 Mold Steel Fabricated by Selective Laser Melting
}

\author{
Shi-Feng Wen ${ }^{1}$, Xian-Tai ji ${ }^{1}$, Yan Zhou ${ }^{1,2^{*}}$, Chang-Jun Han ${ }^{1}$, Qing-Song Wei ${ }^{1}$ and Yu-Sheng Shi ${ }^{1}$
}

\begin{abstract}
The selective laser melting (SLM) method has a great potential for fabricating injection mold with complex structure. However, the microstructure and performance of the SLM molds show significantly different from those manufactured by traditional technologies. In this study, the microstructure, hardness and especially corrosion behavior of the samples fabricated by SLM and casting were investigated. The XRD results exhibit that the $\gamma$-Fe phase is only obtained in the SLM parts, and the a-Fe peak slightly moves to low diffraction angle compared with casting counterparts. Due to the rapid cooling rate, the SLM samples have fine cellular microstructures while the casting ones have coarse grains with obvious elements segregation. Besides, the SLM samples show anisotropy, hardness of side view and top view are 48.73 and $50.31 \mathrm{HRC}$ respectively, which are $20 \%$ higher than that of casting ones. Corrosion results show that the SLM samples have the better anti-corrosion resistance (in a $6 \% \mathrm{FeCl}_{3}$ solution for $48 \mathrm{~h}$ ) but the deeper corrosion pits than casting ones. Finally, the performance of the SLM molds could meet the requirement of injecting production. Moreover, the molds especially present a significant decrease (20\%) of cooling time and increases of cooling uniformity due to the customized conformal cooling channels.
\end{abstract}

Keywords: Selective laser melting, S136 mold steel, Corrosion behavior, Conformal-cooling channels

\section{Introduction}

Injection molds were widely used for mass production of thermoplastic parts with a high production efficiency [1]. The quality of injection production is related to the mold steel materials [2] and the structure [3, 4]. Particularly, cooling channels in molds greatly affect the productivity, product deformation and die life $[5,6]$. Conventional straight-line channels easily cause a heterogeneous heat dissipation and cooling due to the inconsistency between channels and mold cavities. Moreover, the heterogeneous cooling will increase the cooling time [7], even result in some defects such as part warping and sink marks [2, 8]. By contrast, the emerging conformal cooling channels that conform to mold cavities can bring into a steady and homogeneous heat transfer from the cavity surfaces to the coolant, which improves directly the product quality [9]. However, it is difficult to fabricate molds with

\footnotetext{
*Correspondence: zhouyan@cug.edu.cn; yzhou-1987@163.com ${ }^{1}$ State Key Laboratory of Materials Processing and Die \& Mold Technology, School of Materials Science and Technology, Huazhong University of Science and Technology, Wuhan 430074, China Full list of author information is available at the end of the article
}

conformal cooling channels by traditional manufacturing techniques, such as machining, and electrical discharge machining (EDM).

Selective laser melting (SLM), one of the additive manufacturing (AM) technologies, is able to fabricate complex metal parts with a high density layer by layer from 3D CAD data $[10,11]$. Recently, SLM has become one of the most promising AM routes for fabricating metal tools and molds due to its ability to create intricate structure, consequently attracted the attention of both industry and academia [12]. Previous researches have successfully used SLM to manufacture conformal cooling channels for injection molds [13], forging dies [14] and die-casting molds [5]. Meantime, many studies investigated the microstructure and mechanical properties of mold steel fabricated by SLM [15-22]. Zhao et al. [15, 16] developed a high-dense AISI 420 steel by SLM for injection molds. The hardness and the tensile strength reached 50.7 HRC and $1045 \mathrm{MPa}$ respectively, showing a good potential for practical application. Mertens et al. [18] fabricated an H13 mold steel by SLM using different powder-bed preheating temperatures to improve hardness and tensile 
properties. The more homogeneous microstructure and better mechanical properties were obtained at the preheating temperature of $400{ }^{\circ} \mathrm{C}$ comparable to those of wrought $\mathrm{H} 13$ counterparts. A TiC-reinforced H13 steel with enhanced wear resistance was in situ synthesized by SLM [20], which make it very attractive candidate materials for future tooling applications. Except the hardness, mechanical properties and wear resistance that mentioned above, the corrosion resistance is also one of the most important performances that affect the quality of die and mold. Because the injection molds are generally exposed to the acidic environment due to the decomposition of thermoplastics [23]. Nevertheless, to the best of authors' knowledge, the studies on the corrosion behavior of the SLM samples for molds are limited.

S136 mold steel modified from AISI 420, shows favorable mechanical properties and outstanding corrosion resistances [24]. It currently becomes one of the most widely used materials for injection molds. However, few studies focus on the SLM S136 steel. Therefore, this study are to characterize the microstructure and hardness of S136 steel fabricated by SLM; to evaluate the corrosion resistance of as-SLM S136 steel through chemical corrosion; and to compare the differences in microstructure, hardness and corrosion resistance of as-SLM and casting S136 alloys.

\section{Materials and Methods}

\subsection{Feedstock Materials}

The raw casting S136 bars with a diameter of $30 \mathrm{~mm}$ were supplied by ASSAB, Sweden. The casting specimens were directly cut from the raw casting bars by machining. The S136 powder for SLM was produced by gas atomization method (Changsha Hualiu Metallurgy Powder Co, Ltd., China) from the raw casting bars. The particle morphology (SEM, JSM-7600F Japan) and the powder size distribution (Mastersizer 3000, Worcestershire United Kingdom) are shown in Figure 1. The powders appear in a nearly spherical shape and have an average particle size of $25.2 \mu \mathrm{m}$. The chemical composition of the S136 powder (confirmed by the inductively coupled plasma optical emission spectrometry, ELAN DRC-e, PerkinElmer, USA and oxygen/nitrogen/hydrogen, ONH836, LeCroy, USA) is given in Table 1 .

\subsection{SLM Machine and Process}

The HRPM-II SLM machine developed by Rapid Manufacturing Center, Huazhong University of Science and Technology (HUST) was used for SLM experiments. It was equipped with a continuous wave fiber laser (the maximum output of $400 \mathrm{~W}$, the wavelength of $1.064 \mu \mathrm{m}$, the spot size of $0.08 \mathrm{~mm}$ ). Some cubic specimens in dimensions of $10 \mathrm{~mm}$ (in length) $\times 10 \mathrm{~mm}$ (in

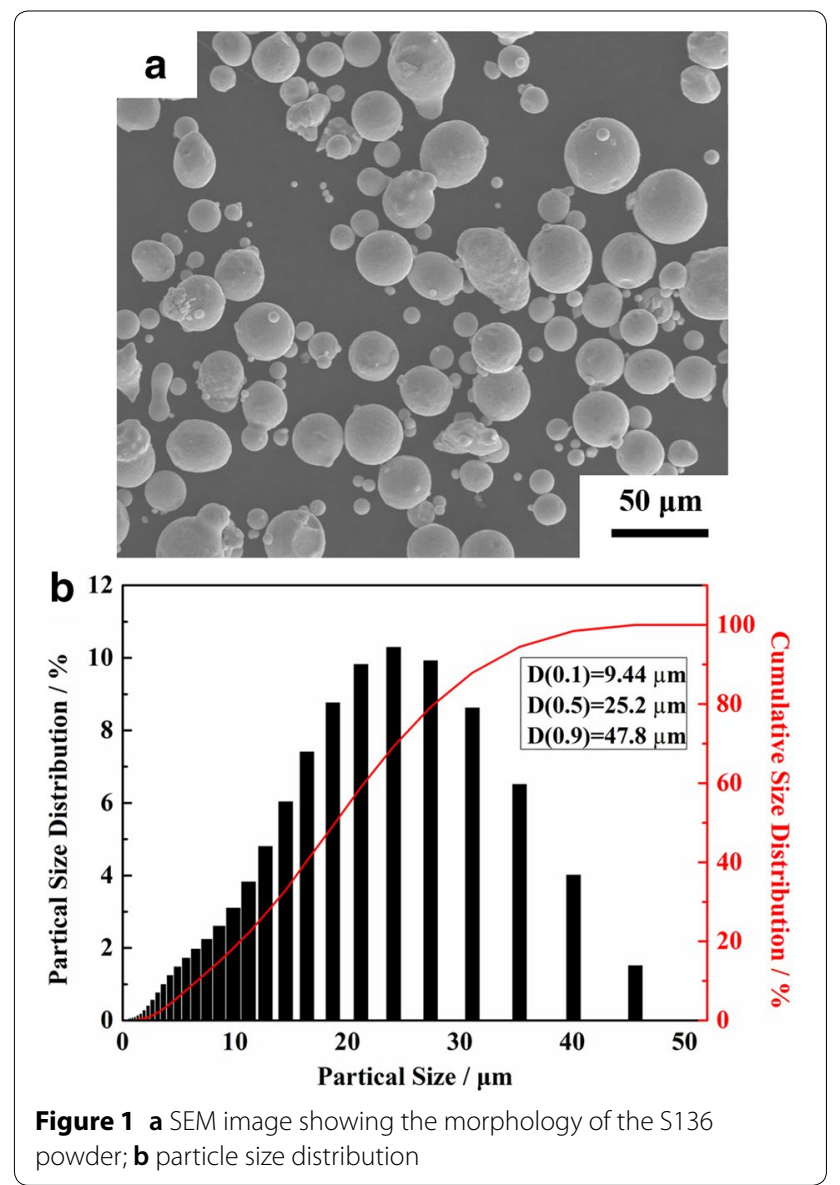

width) $\times 10 \mathrm{~mm}$ (in height) were fabricated by SLM with a set of optimized parameters: laser power, $280 \mathrm{~W}$; scanning speed, $1000 \mathrm{~mm} / \mathrm{s}$; scanning space, $0.07 \mathrm{~mm}$; and layer thickness, $0.03 \mathrm{~mm}$. The whole process of SLM was performed in a high purity nitrogen atmosphere $(99.9 \%)$ to avoid oxidation. The long bidirectional scanning strategy was used for sample fabrication as shown in Figure 2(a). Melt tracks and melt track boundaries in top view were depicted in Figure 2(b).

\subsection{Characterization}

XRD measurements were conducted on a XRD-7000S machine (Shimadzu, Japan) with a $\mathrm{Cu}$ tube at $40 \mathrm{kV}$ and $30 \mathrm{~mA}$. The diffraction angle of $2 \theta$ varied from $30^{\circ}$ to $100^{\circ}$ with a continuous scan mode at $10^{\circ} / \mathrm{min}$. The polishing surfaces of the samples were characterized by a digital optical microscope (OM, VHX-1000C, KEYENCE, Japan). The micro morphologies were observed using a JSM-7600F Field Emission Scanning Electron Microscope (JEOL, Japan). The prepared samples were hot mounted. Then the surfaces of samples were grounded and polished by an automatic polishing machine 
Table 1 Chemical composition (wt\%) of S136 powder

\begin{tabular}{llllllll}
\hline $\mathbf{S i}$ & Mn & Cr & V & C & O & P & S \\
\hline 0.96 & 0.98 & 13.55 & 0.4 & 0.29 & 0.078 & 0.01 & Fe \\
\hline
\end{tabular}

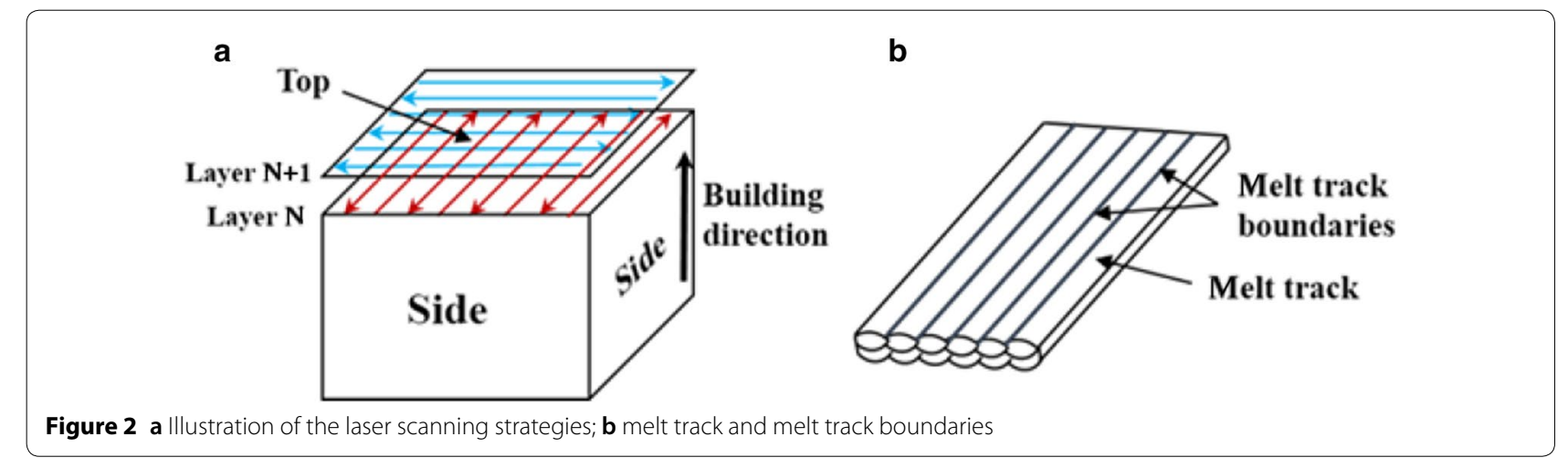

(Automet300, Buehler, America). A reagent consisting of $5 \mathrm{~g} \mathrm{FeCl}_{3}, 15 \mathrm{~mL} \mathrm{HCl}$, and $60 \mathrm{~mL} \mathrm{H}_{2} \mathrm{O}$ was used as corrosive liquid. The Rockwell hardness was measured using a hardness tester (600MRD, Wolpert, America). For each sample, ten points at random positions were measured to obtain the average value of hardness.

\subsection{Corrosion Tests}

All surfaces of the samples were grounded using $\mathrm{SiC}$ papers from 400 to 2000 grits, and cleaned with ethanol liquid. A Mettler Toledo AL204 analytical balance (Switzerland) with the smallest increment of $0.01 \mathrm{mg}$ was used for all weight measurements. Then, the samples were immersed in a $6 \% \mathrm{FeCl}_{3}$ solution [25] at $50 \pm 2{ }^{\circ} \mathrm{C}$ for $48 \mathrm{~h}$, get out every $2 \mathrm{~h}$ in first $12 \mathrm{~h}$ and then every $12 \mathrm{~h}$. Subsequently, they were rinsed with distilled water, dipped in acetone, dried in hot air, weighed, and re-immersed [26]. The surfaces of samples after corrosion were characterized with optical microscopy (OM) equipped a digital microscopy (VHX-1000, Keyence, Japan).

\section{Results and Discussion}

\subsection{Phase Analysis}

The XRD patterns of S136 samples manufactured by SLM, the casting sample and the gas-atomized powder are illustrated in Figure 3. The diffraction peaks of the BCC structural $\alpha$-Fe can be observed in all samples. Different from the casting S136, the powder and as-SLM S136 also includes austenite $\gamma$-Fe phase, which is similar with the results from previous observations during SLM of AISI 420 [16, 27]. Based on the XRD patterns, the volume fractions of the alloy phases were estimated by the reference intensity ratio method (RIR) [28] and listed in
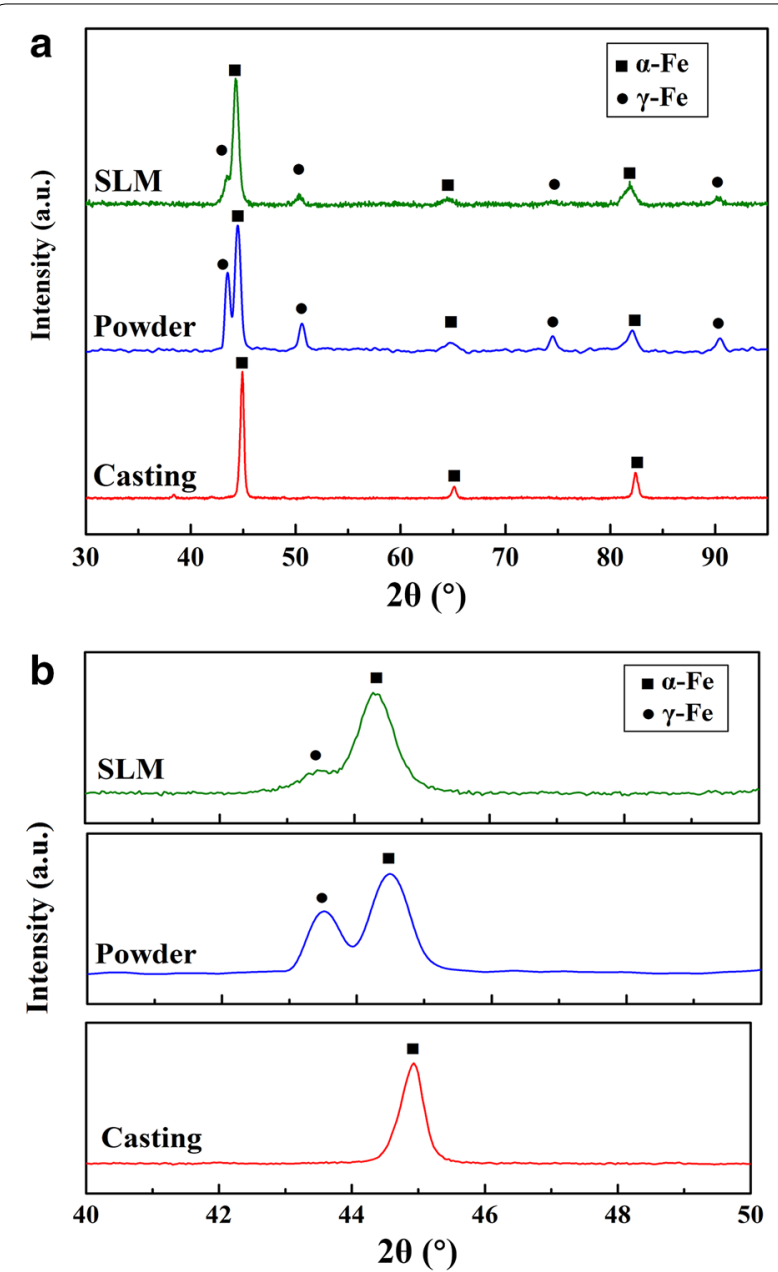

Figure 3 XRD patterns of a S136 powder, casting and SLM part; $\mathbf{b}$ enlargement of the a-Fe diffraction peak 
Table 2 Volume fraction of the detected phase

\begin{tabular}{llc}
\hline Samples & a-Fe phase (\%) & $\boldsymbol{\gamma}$-Fe phase (\%) \\
\hline Casting & 100 & 0 \\
Powder & 63 & 37 \\
SLM & 78 & 22 \\
\hline
\end{tabular}

Table 2. It is well known that S136 alloys may have several crystalline structures according to the $\mathrm{Fe}-\mathrm{C}$ equilibrium phase diagram. The $\alpha$-Fe phase is transformed into $\gamma$-Fe when casting parts is melted. Then the $\gamma \rightarrow \alpha$ transformation occurs when temperatures drop to the ambient temperature during gas atomization [15]. In addition, the volume fractions of $\alpha$-Fe phase in powder is lower than that in SLM part. It can be attributed to the faster cooling rate in SLM process compared with gas atomization.

Besides, it can be seen that the bases of the peaks in SLM part are comparatively wider than that in casting. This suggests that the crystal lattice structures of SLM part are experiencing certain level of internal stresses that are thermally induced during the rapid solidification SLM process $[29,30]$. Moreover, it can be found that the $\alpha$-Fe diffraction peak of as-SLM S136 slightly moved left compared with that of casting, as depicted in Figure 3(b). It might be associated with the generation of residual stresses [31], the existence of retained austenite as well as the martensitic transformation that often occurred in the process of SLM [32,33].

\subsection{Microstructures}

Figure 4 shows OM images of the cross sections of asSLM and casting samples. Compared with casting S136, the pore number of as-SLM samples seems to be more. The pore size varied from a few microns to one hundred microns, and it may be the result of the incomplete fusion between successive molten layers.
Figure 5 shows SEM images of the microstructure of as-SLM and casting S136 samples. The refining effect of the SLM process is clearly reflected in the microstructure. The cooling rate during the SLM process is calculated to reach up to $10^{5} \mathrm{~K} / \mathrm{s}$ [34], while the cooling rate in the casting process is about $10-70 \mathrm{~K} / \mathrm{s}$ [35]. The increased cooling rate leads to an insufficient growth of the grain. Thus, the SLM-processed samples display significantly fine grain microstructure with the approximate size of $1 \mu \mathrm{m}$ (Figure 5(a) and 5(b)). The microstructure of melting track in top view of SLM-processed sample reveals two distinct regions: equiaxed fine grains and cellular dendrite grains. The formation of two regions is due to the different thermal behavior inside and on the edge of the melt track, suggesting that the final microstructure is a thermally modified solidified structure (Figure 5(a)). In the side view (Figure 5(b)), the processing nature of SLM can be identified through the elongated columnar grains that grow along the building direction. The similar microstructure was found in the fabrication of $\mathrm{H} 13$ by SLM [20]. While in the casting sample, the coarse carbide network is already clearly visible at the same magnification (Figure 5(c)). In Figure 5(d) EDX point analysis of casting state shows that $\mathrm{C}$ and $\mathrm{Cr}$ are present in the carbide network. However, the SLM-processed sample reveals a homogeneous distribution of alloying elements and carbides could not be found. This may be associated with the rapid solidification during SLM that prevents the precipitation of carbides [10], and the fully re-melting of the material within the small molten pools that the temperature of the melting pool is high enough to dissolve chromium carbides phases [20].

\subsection{Hardness}

Figure 6 illustrates the hardness values of S136 steel fabricated by SLM, as well as those of casting counterparts. The hardness values (48.73-50.31 HRC) of
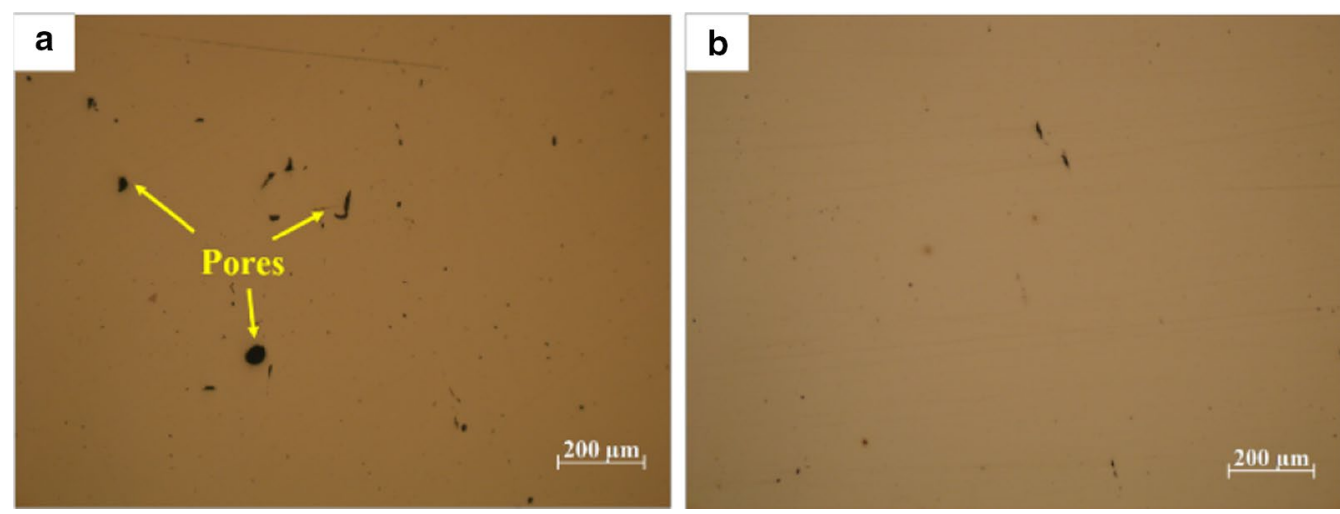

Figure 4 The OM images of polished cross section of $\mathbf{a}$ SLM-processed sample; $\mathbf{b}$ casting sample 

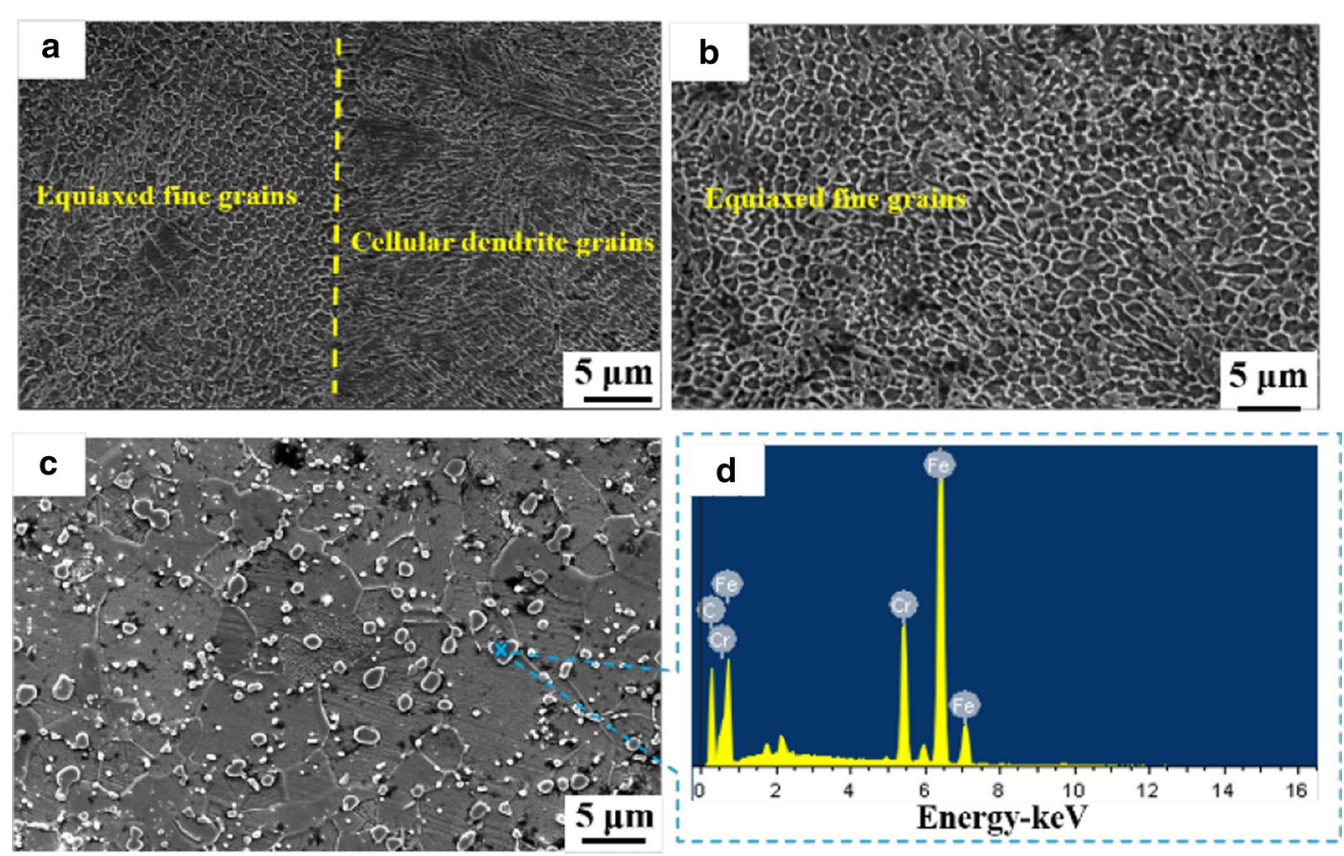

Figure 5 Microstructure of the SLM-produced and casting S136 parts: a the top view of SLM sample showing two distinct regions; $\mathbf{b}$ the side view of SLM sample revealing equiaxed fine grains; $\mathbf{c}$ casting state; $\mathbf{d}$ EDX point analysis

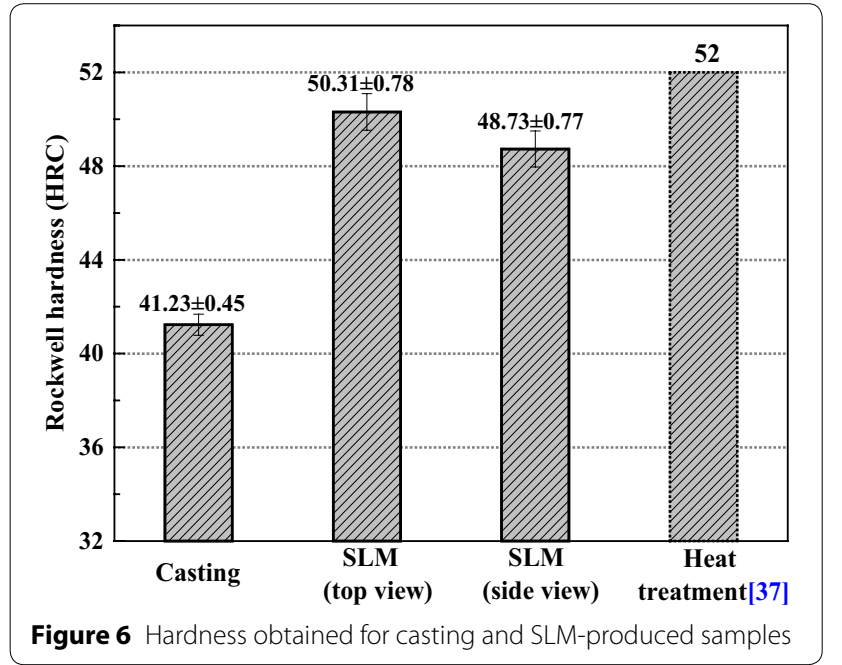

as-SLM samples are about $20 \%$ higher than those of casting ones (41.23 HRC), and comparable to those of S136 alloys processed by austenitizing heat treatment (52 HRC) [36]. This difference might be attributed to the combined effect of high hard $\gamma$ phase and the finer grains in as-SLM samples. Thijs [37] found that the crystallographic texture in as-SLM tantalum alloys was the dominant cause for the difference in hardness values along different directions. In addition, Sander [38] pointed out that the finer grains in as-SLM alloys had an effect on hardness enhancement. According to HallPetch relationship [39]

$$
\sigma_{0}=\sigma_{i}+\frac{k}{d^{1 / 2}},
$$

where $\sigma_{0}$ is the hardness of a metal, $\sigma_{i}$ is the applied stress, $k$ is the strengthening coefficient (a constant specific to each material), and $d$ is the average grain diameter. Reducing the grain size will cause the material to become stronger. On the other hand, the finer the initial grains, the more significant the pile-up effect of dislocations at grain boundaries and the larger the resistance of the dislocations to slip transfer. Consequently, when subjected to external forces, the zones of melt pool with finest grains are harder to deform compared with the other zones [40]. Furthermore, the hardness values on top view (50.31 HRC) of as-SLM samples are slightly higher than those on side view (48.73 HRC), showing an anisotropic feature similar to some previous reports [41-43]. This can be explained by the different thermal history at the two surfaces [44], resulting in microstructure changes. The loading applied at the top view corresponds to more grain boundaries than that at the side view [45]. The grain boundaries could resist to the deformation more effectively and thus the measured hardness from the top view has a higher value. To compare with some other steel alloys processed by SLM, we can found that the hardness values of as-SLM S136 is remarkably $25 \%$ and $9 \%$ higher 
than $18 \mathrm{Ni300}$ mold steel [46] and AISI 420 mold steel [15], respectively.

\subsection{Corrosion Behaviors}

The weight-loss curves of samples immersed in the $\mathrm{FeCl}_{3}$ solution are shown in Figure 7. After $48 \mathrm{~h}$, the average mass loss of the as-SLM samples is $3.47 \pm 0.2 \mathrm{mg} / \mathrm{cm}^{2}$, lower than that of the casting samples $(4.16 \pm 0.03 \mathrm{mg} /$ $\mathrm{cm}^{2}$ ). Hill [47] pointed out that the corrosion resistance of austenite was higher than that of ferrite/martensite, because the austenite possessed lower internal stresses and less defects. As a result, the residual austenite $\gamma$-Fe phase in as-SLM S136 steel could be beneficial to promote the corrosion resistance. On the other hand, Leon [48] also emphasized that more homogenous microstructure was a favorable factor for the enhancement of corrosion resistance. During SLM process, a very high solidification rate could result in much more homogenous microstructure, together with an improved dissolution of alloying elements but nearly without any precipitates. However, compared with the SLM-processed S136, an obvious elements segregation in casting samples, which led to the decline of chromium content in metal matrix, and thus reduce the corrosion resistance of alloys [49-51]. Besides, the mass loss curve of SLM samples have a poor reproducibility, which is also different with the casting curves. This difference may be resulted from the nature of SLM manufacturing method, which produces a part layer by layer and the defects are distributed randomly. Therefore, the properties of SLM samples are diverse even though they are fabricated in same parameters.

Figure 8 illustrates $\mathrm{OM}$ and digital microscopic images of samples' surfaces after chemical immersion.

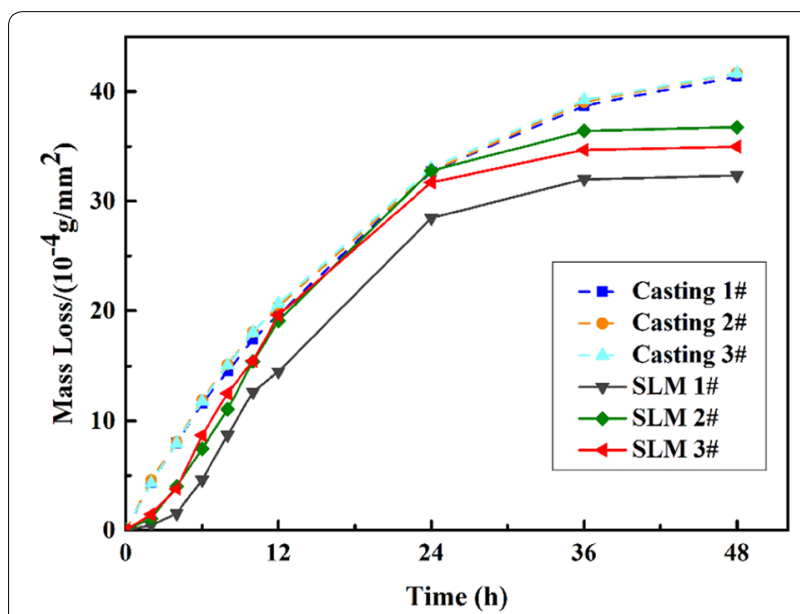

Figure 7 Mass loss curves of the S136 samples fabricated by SLM and casting in $6 \% \mathrm{FeCl}_{3} \cdot 6 \mathrm{H}_{2} \mathrm{O}$ for $48 \mathrm{~h}$
Many corrosion pits in different sizes and shapes could be observed on the corrosion surfaces. The top and side surfaces of as-SLM samples have different corrosion morphologies. On the top view (Figure 8(a)), some near-round pits are mainly distributed around melt track where the phenomenon such as stress, grain coarsening, and element segregation is easier to produce $[52,53]$. Consequently, those zones eroded severely and relatively larger corrosion pits generated. The size of pits ranges from dozens of micron to about $200 \mu \mathrm{m}$. Figure 8(b) shows that the maximum corrosion depth is about $155 \mu \mathrm{m}$. On the side view (Figure 8(c)), some continuous grooves distribute side by side on the surfaces. In the process of SLM, an obvious boundary will be generated between layers, also known as "layer-layer" molten pool boundaries. Those grooves might be resulted from the corrosion of the boundaries between layers where have weak metallurgical bonding. The width of the groove is about $200-300 \mu \mathrm{m}$, and the maximum depth is $531.3 \mu \mathrm{m}$ (Figure 8(d)). In comparison, the side surfaces seem to be more serious corrosion degree. It also should be related to the differences in the morphologies and characteristics of melt track boundaries on top and side views described above.

Different from those on as-SLM samples, many fine corrosion pits are evenly distributed on the surfaces of casting samples (Figure 8(e)). The size of the corrosion pits is just a few microns, and the maximum corrosion depth is only $75.51 \mu \mathrm{m}$ (Figure 8(f)). However, the number and the density of corrosion pits are much higher than those of as-SLM samples, resulting in a greater degree of corrosion. This kind of difference could be explained by the differences in microstructures of SLM and casting. The corrosion in as-SLM samples mainly initiates at melt track boundaries, having a feature of locality and anisotropic because of the special metallurgical process of SLM. Differently, the corrosion in casting samples mainly starts along the grain boundaries. Therefore, the corrosion pits in casting samples distribute more uniformly because of those uniform equiaxed grains.

The results obtained by the immersion tests indicate that the corrosion resistance of the as-SLM samples is better than casting ones. This is manifested by the fact that the mass loss is slightly lower for the casting samples. It can be mainly attributed to the differences between the microstructure characteristics as mentioned above. The increased solidification rate obtained by the SLM process has resulted in gaining a much more homogenous microstructure with improved dissolution of alloying elements and impurities with nearly no precipitates. Altogether, this microstructure has a beneficial effect on the corrosion resistance [52]. Although the mass loss of as-SLM samples is lower, the corrosion pits are deeper. This may 

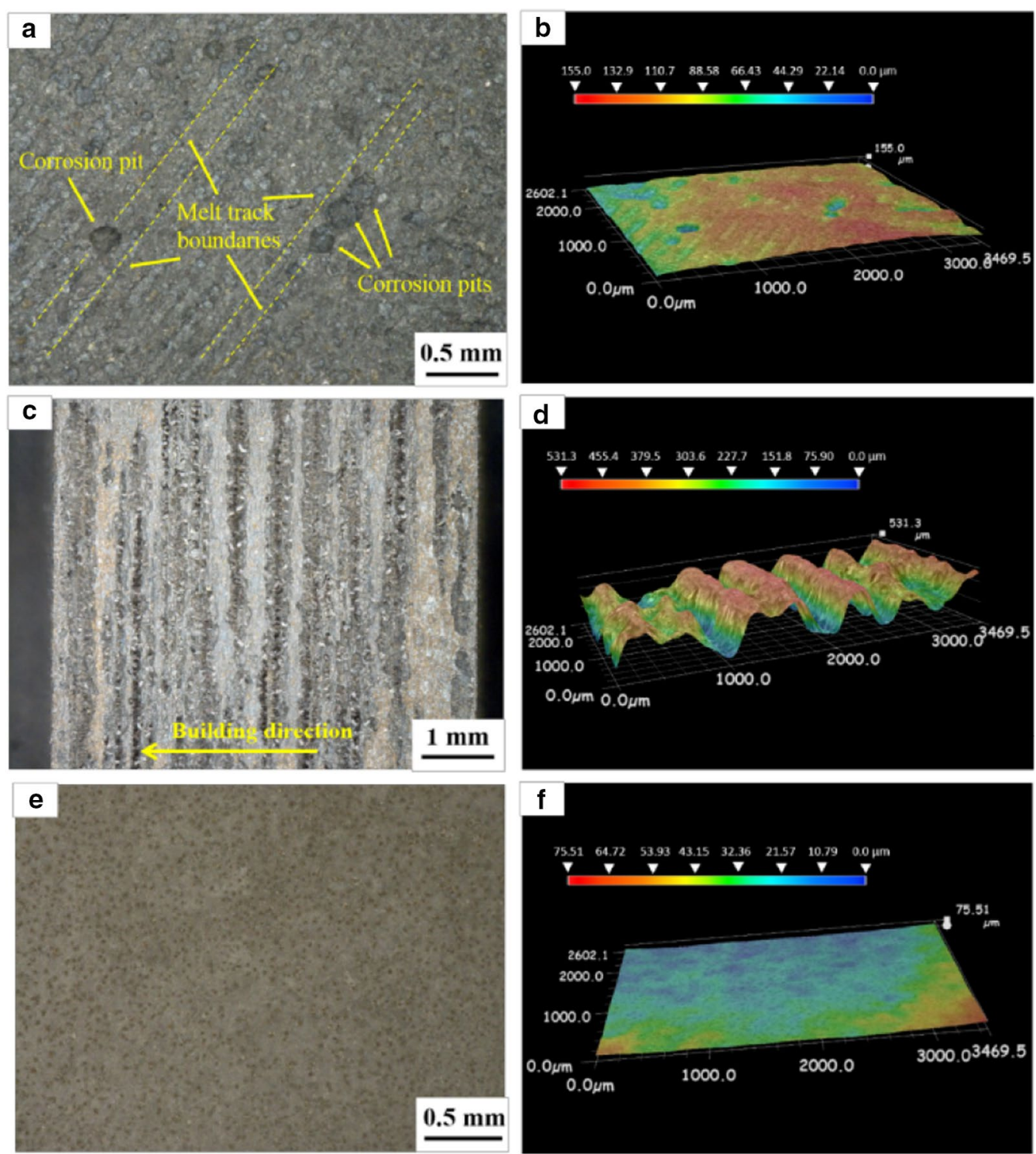

Figure 8 Surface photographic and digital microscopic images of specimens immersed in $6 \% \mathrm{FeCl}_{3} \cdot 6 \mathrm{H}_{2} \mathrm{O}$ for $48 \mathrm{~h}$ : $\mathbf{a}$, $\mathbf{b}$ top view of as-SLM samples; c, $\mathbf{d}$ side view of as-SLM samples; $\mathbf{e}, \mathbf{f}$ casting samples

be related to the un-melted powders or impurity formed by spatter in the sample, as shown in cross-section of corroded part (Figure 9). The area where contains unmelted powder is vulnerable in corrosion attack, and as the matrix dissolved to the acid solution, powder fall off to the liquid, which accelerates the corrosion and deepen the pits somewhat.

\subsection{Case Study}

A kind of transparent box cover was made of recycling PET (R-PET). The covers were produced by a conventional mold (Figure 10(a)). During the production, temperature difference between mold inserts gate $\left(20^{\circ} \mathrm{C}\right)$ and the molten plastic $\left(270{ }^{\circ} \mathrm{C}\right)$ is huge. Moreover, the design of the mold insert cannot extract heat quickly. As a result, defect formed at the insert gate, as shown in Figure 11(a).

The SLM can fabricate complex cooling channels, which addresses the limitations of traditional method. A complex channels network is designed to improve the cooling efficiency, as depicted in Figure 10(b). Then a mold insert with conformal-cooling channel was fabricated by SLM, as shown in Figure 10(c) and 10(d). The Figure 11(b) shows the cover formed by SLM-processed 

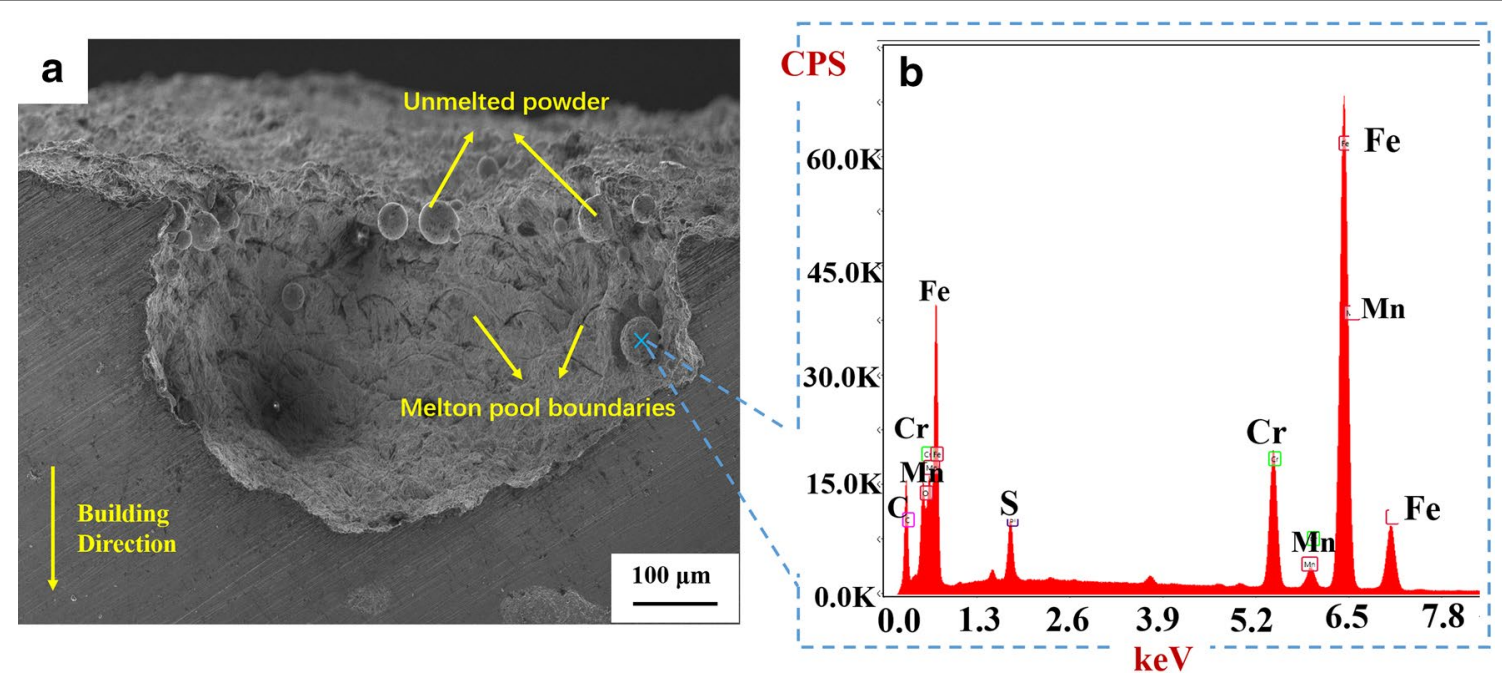

Figure 9 a Corrosion morphology of the cross-section of as-SLM sample; $\mathbf{b}$ EDS point analysis indicates the existing un-melted powder

a

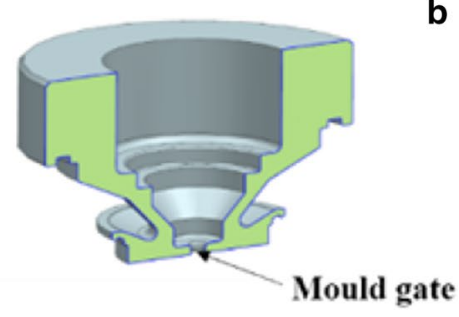

C

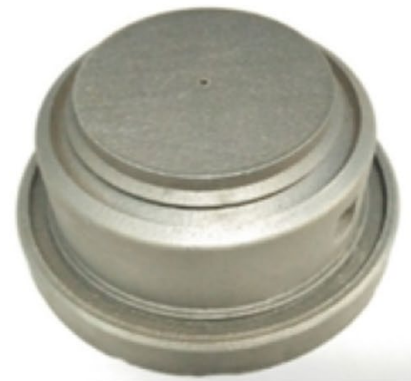

b

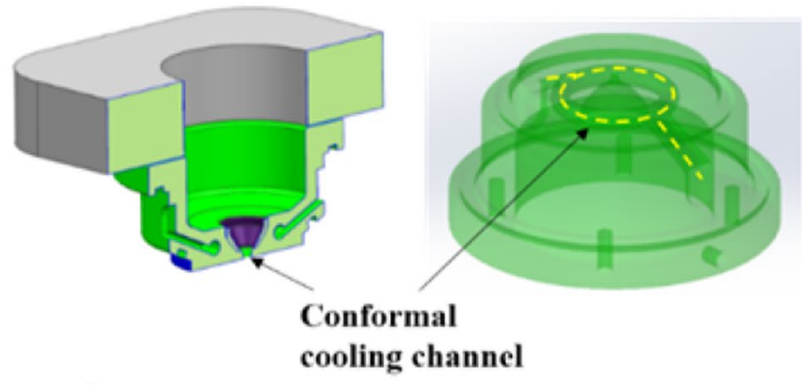

d

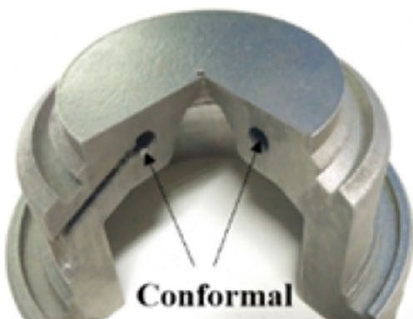

cooling channel

Figure 10 Injection mold insert: a, b CAD model; c, d insert part fabricated by SLM

a

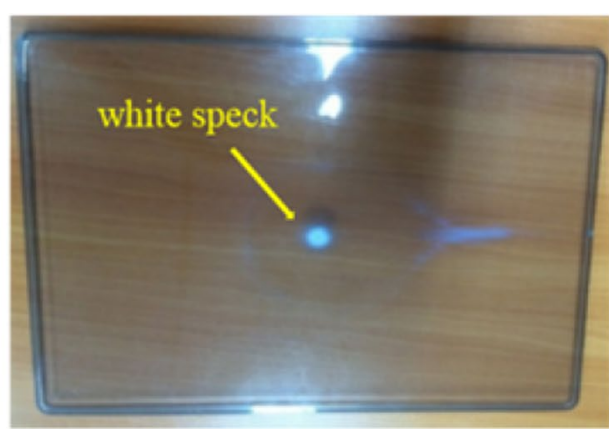

b

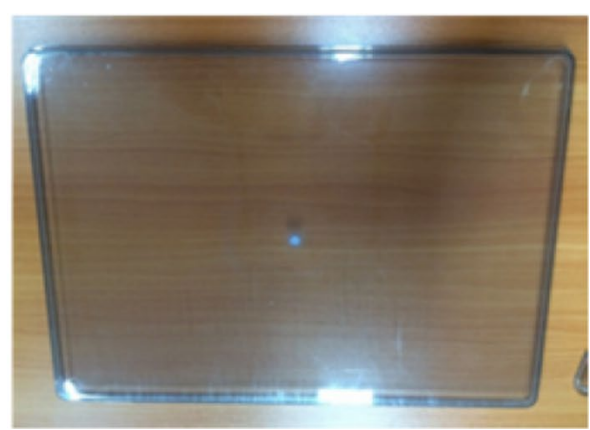

Figure 11 Transparent box covers produced by two kinds of mold: a traditional mold; b SLM mold 
Table 3 Production efficiency of the two kinds of mold inserts

\begin{tabular}{llll}
\hline & $\begin{array}{l}\text { Filling } \\
\text { and holding time } \\
\text { (s) }\end{array}$ & $\begin{array}{l}\text { Cooling } \\
\text { time }(\mathbf{s})\end{array}$ & $\begin{array}{l}\text { Production } \\
\text { cycle (s) }\end{array}$ \\
\hline SLM insert & 7 & 16 & 40 \\
Traditional insert & 7 & 25 & 48 \\
\hline
\end{tabular}

mold. The area of the white burn mark becomes smaller. The production efficiency of the two kinds of mold inserts is illustrated in Table 3. SLM-processed conformal cooling inserts reduced cooling and cycle times by 20\%-36\% over conventional machined inserts, leading to a higher productivity. This work identifies that the SLM method shows great potential in fabricating injection mold with conformal cooling channel and complex geometries in the future.

\section{Conclusions}

This study mainly investigates the corrosion behavior of S136 mold steel fabricated by SLM and casting, and the microstructure and hardness are also discussed. The major findings are concluded as follows.

(1) The $\alpha$-Fe phases are obtained both in SLM-processed and casting samples while $\gamma$-Fe phase only exists in the SLM-processed S136. Compared to the casting S136, the SLM-processed specimen exhibits very fine grains about $1 \mu \mathrm{m}$.

(2) The top view of SLM-processed parts shows the highest hardness of $50.31 \mathrm{HRC}$, while the side view is 48.73 HRC. The hardness of casting samples is 41.23 HRC, which is obviously less than the SLMprocessed parts.

(3) In the $6 \% \mathrm{FeCl}_{3}$ solution immersion test, casting samples have a greater mass loss $(4.16 \pm 0.03 \mathrm{mg} /$ $\left.\mathrm{cm}^{2}\right)$ than the SLM-processed parts $(3.47 \pm 0.2 \mathrm{mg} /$ $\mathrm{cm}^{2}$ ), but the surfaces of SLM-processed specimens have a much worse destroy than the castings.

(4) A case of SLM-processed S136 mold with conformal cooling channel is used, which can reduce cycle times and increases cooling uniformity during the injection process.

\section{Authors' Contributions}

S-FW and X-TJ were in charge of the whole trial; YZ together with Q-SW and Y-SS wrote the manuscript; C-JH assisted with sampling and laboratory analyses. All authors read and approved the final manuscript.

\section{Author Details}

${ }^{1}$ State Key Laboratory of Materials Processing and Die \& Mold Technology, School of Materials Science and Technology, Huazhong University of Science and Technology, Wuhan 430074, China. ${ }^{2}$ Faculty of Engineering, China University of Geosciences, Wuhan 430074, China.

\section{Authors' Information}

Shi-Feng Wen, born in 1979, is currently a lecturer at State Key Laboratory of Materials Processing and Die \& Mold Technology, Huazhong University of Science and Technology, China. His research interests include additive manufacturing.

Xian-Tai Ji, born in 1992, is currently a master candidate at State Key Laboratory of Materials Processing and Die \& Mold Technology, Huazhong University of Science and Technology, China.

Yan Zhou, born in 1987, is currently an associate professor at Faculty of Engineering, China University of Geosciences, China. Her research interests include selective laser melting.

Chang-Jun Han, born in 1991, is currently a doctoral candidate at State Key Laboratory of Materials Processing and Die \& Mold Technology, Huazhong University of Science and Technology, China.

Qing-Song Wei, born in 1975, is currently a professor and a PhD candidate supervisor at State Key Laboratory of Materials Processing and Die \& Mold Technology, Huazhong University of Science and Technology, China. His research interests include additive manufacturing.

Yu-Sheng Shi, born in 1962, is currently a professor and a PhD candidate supervisor at State Key Laboratory of Materials Processing and Die \& Mold Technology, Huazhong University of Science and Technology, China. His research interests include additive manufacturing.

\section{Acknowledgements}

The authors sincerely thanks to Professor Chun-Ze Yan of Huazhong University of Science and Technology for his critical discussion and reading during manuscript preparation.

\section{Competing Interests}

The authors declare that they have no competing interests.

\section{Funding}

Supported by National Natural Science Foundation of China (Grant No. 51605176), National Hi-tech R\&D Program of China (863 Program, Grant No. 2015AA042501). Hubei Provincial Natural Science Foundation of China (Grant No. 2018CFB502), Guangdong Provincial Technology Major Project of China (Grant No. 2017B09091 1007), State Key Laboratory of Materials Processing and Die \& Mould Technology, Huazhong University of Science and Technology (Grant No. P2019-006), and Engineering Research Center of Rock-Soil Drilling \& Excavation and Protection, Ministry of Education (Grant No. 201804).

\section{Publisher's Note}

Springer Nature remains neutral with regard to jurisdictional claims in published maps and institutional affiliations.

Received: 13 November 2017 Accepted: 13 December 2018 Published online: 24 December 2018

\section{References}

[1] M Kurt, O S Kamber, Y Kaynak, et al. Experimental investigation of plastic injection molding: Assessment of the effects of cavity pressure and mold temperature on the quality of the final products. Materials \& Design, 2009, 30: 3217-3224.

[2] S. Lei, Y Xiao, T Kuang, et al. Fracture failure analysis of S136 steel plastic mold by EPMA. Journal of Chinese Electron Microscopy Society, 2010, 29: 535-539.

[3] R Raviwongse, V Allada. Artificial neural network based model for computation of injection mould complexity. The International Journal of Advanced Manufacturing Technology, 1997, 13(8): 577-586.

[4] K M Au, K M Yu. A scaffolding architecture for conformal cooling design in rapid plastic injection moulding. The International Journal of Advanced Manufacturing Technology, 2007, 34(5-6): 496-515.

[5] Z Shayfull, S Sharif, A M Zain, et al. Milled groove square shape conformal cooling channels in injection molding process. Materials \& Manufacturing Processes, 2013, 28: 884-891. 
[6] C L Li. A feature-based approach to injection mold cooling system design. Computer-Aided Design, 2001, 33(14): 1073-1090.

[7] C J Smith, F Derguti, E H Nava, et al. Dimensional accuracy of Electron Beam Melting (EBM) additive manufacture with regard to weight optimized truss structures. Journal of Materials Processing Technology, 2016, 229: 128-138.

[8] A Armillotta, R Baraggi, S Fasoli. SLM molding for die casting with conformal cooling channels. The International Journal of Advanced Manufacturing Technology, 2014, 71: 573-583.

[9] D G Ahn. Applications of laser assisted metal rapid molding process to manufacture of molding \&forming molds-state of the art. International Journal of Precision Engineering and Manufacturing, 2011, 12(5): 925-938.

[10] P Krakhmalev, I Yadroitsava, G Fredriksson, et al. In situ heat treatment in selective laser melted martensitic AISI 420 stainless steels. Materials \& Design, 2015, 87: 380-385.

[11] J A Cherry, H M Davies, S Mehmood, et al. Investigation into the effect of process parameters on microstructural and physical properties of $316 \mathrm{~L}$ stainless steel parts by selective laser melting. International Journal of Precision Engineering and Manufacturing, 2015, 76: 869-879.

[12] Z Sun, X Tan, S Tor, et al. Selective laser melting of stainless steel $316 \mathrm{~L}$ with low porosity and high build rates. Materials \& Design, 2016, 104: 197-204.

[13] B Hadley. Design of conformal cooling layers with self-supporting lattices for additively manufactured tooling. Additive Manufacturing, 2016, 11: 16-22.

[14] R Hölker, A E Tekkaya. Advancements in the manufacturing of dies for hot aluminum extrusion with conformal cooling channels. The International Journal of Advanced Manufacturing Technology, 2016, 83(5-8): 1209-1220

[15] X Zhao, Q Wei, B Song, et al. Fabrication and characterization of AISI 420 stainless steel using selective laser melting. Materials and Manufacturing Processes, 2015, 30(11): 1283-1289.

[16] X Zhao, B Song, Y Zhang, et al. Decarburization of stainless steel during selective laser melting and its influence on Young's modulus, hardness and tensile strength. Materials Science and Engineering: A, 2015, 647: 58-61.

[17] M J Holzweissig, A Taube, F Brenne, et al. Microstructural characterization and mechanical performance of hot work mold steel processed by selective laser melting. Metallurgical and Materials Transactions B, 2015, 46(2): 545-549.

[18] R Mertens, B Vrancken, N Holmstock, et al. Influence of powder bed preheating on microstructure and mechanical properties of $\mathrm{H} 13$ mold steel SLM parts. Physics Procedia, 2016, 83: 882-890.

[19] B T Hermann, D Dimitrov. The achievable mechanical properties of SLM produced maraging steel 300 components. Rapid Prototyping Journal 2016, 22(3): 487-494

[20] B AlMangour, D Grzesiak, J M Yang. Nanocrystalline TiC-reinforced H13 steel matrix nanocomposites fabricated by selective laser melting. Materials \& Design, 2016, 96: 150-161.

[21] A G Demir, P Colombo, B Previtali. From pulsed to continuous wave emission in SLM with contemporary fiber laser sources: effect of temporal and spatial pulse overlap in part quality. The International Journal of Advanced Manufacturing Technology, 2017: 1-14.

[22] M Mazur, M Leary, M McMillan, et al. SLM additive manufacture of H13 mold steel with conformal cooling and structural lattices. Rapid Prototyping Journal, 2016, 22(3): 504-518.

[23] D Papageorgiou, C Medrea, N Kyriakou. Failure analysis of H13 working die used in plastic injection molding. Engineering Failure Analysis, 2013, 35: 355-359.

[24] D Zhang, J Liu, Y Chen, et al. Investigation on S-136 steel surface planarization by chemical mechanical polishing. Microelectronic Engineering, 2015, 134: 47-53.

[25] ASTM Designation. Standard test methods for pitting and crevice corrosion resistance of stainless steels and related alloys by use of ferric chloride solution. ASTM International 2009, G48-03.

[26] S Lu, K Yao, Y Chen, et al. The effect of tempering temperature on the microstructure and electrochemical properties of a 13 wt\% Cr-type martensitic stainless steel. Electrochimica Acta, 2015, 165: 45-55.
[27] M J Holzweissig, A Taube, F Brenne, et al. Microstructural characterization and mechanical performance of hot work mold steel processed by selective laser melting. Metallurgical and Materials Transactions B, 2015, 46(2): 545-549

[28] C R Hubbard, R L Snyder. RIR-measurement and use in quantitative XRD. Powder Diffraction, 1988, 3(2): 74-77.

[29] Z H Liu, C K Chua, K F Leong, et al. A preliminary investigation on selective laser melting of $\mathrm{M} 2$ high speed steel. 5th International Conference on Advanced Research and Rapid Prototyping, Leiria, Portugal, 2011: $339-346$

[30] Z H Liu, C K Chua, K F Leong, et al. Microstructural investigation of $\mathrm{M} 2$ high speed steel produced by selective laser melting. Photonics Optoelectronics IEEE, 2012: 1-4.

[31] B Song, S Dong, S Deng, et al. Microstructure and tensile properties of iron parts fabricated by selective laser melting. Optics \& Laser Technology, 2014, 56: 451-460.

[32] J P Kruth, P Mercelis, JV Vaerenbergh, et al. Binding mechanisms in selective laser sintering and selective laser melting. Rapid Prototyping Journal, 2005, 11(1): 26-36.

[33] J M Moyer, G S Ansell. The volume expansion accompanying the martensite transformation in iron-carbon alloys. Metallurgical and Materials Transactions A, 1975, 6(9): 1785-1791.

[34] K G Prashanth, B Debalina, Z Wang, et al. Tribological and corrosion properties of Al-12Si produced by selective laser melting. Journal of Materials Research, 2014, 29(17): 2044-2054.

[35] J Hufenbach, L Giebeler, M Hoffmann, et al. Effect of short-term tempering on microstructure and mechanical properties of high-strength FeCrMoVC. Acta Materialia, 2012, 60(11): 4468-4476.

[36] L L Han, C M Lin. Corrosion resistance of ASSAB Stavax ESR stainless steel by heat and cold treatment. Materials Transactions, 2013, 54(5): 833-838.

[37] L Thijs, M L M Sistiaga, R Wauthle, et al. Strong morphological and crystallographic texture and resulting yield strength anisotropy in selective laser melted tantalum. Acta Materialia, 2013, 61(12): 4657-4668.

[38] J Sander, J Hufenbach, L Giebeler, et al. Microstructure and properties of FeCrMovC mold steel produced by selective laser melting. Materials \& Design, 2016, 89: 335-341.

[39] K Kempen, L Thijs, JV Humbeeck, et al. Processing AlSi10 Mg by selective laser melting: parameter optimisation and material characterization. Materials Science and Technology, 2015, 31(8): 917-923.

[40] H Chen, D Gu, D Dai, et al. Microstructure and composition homogeneity, tensile property, and underlying thermal physical mechanism of selective laser melting tool steel parts. Materials Science and Engineering: $A, 2017,682:$ 279-289.

[41] B E Carroll, T A Palmer, A M Beese. Anisotropic tensile behavior of Ti-6Al-4 V components fabricated with directed energy deposition additive manufacturing. Acta Materialia, 2015, 87: 309-320.

[42] T Kimura, T Nakamoto. Microstructures and mechanical properties of A356 (AlSi7Mg0.3) aluminum alloy fabricated by selective laser melting. Materials \& Design, 2016, 89: 1294-1301.

[43] M Mahmoudi, A Elwany, A Yadollahi. Mechanical properties and microstructural characterization of selective laser melted 17-4 PH stainless steel. Rapid Prototyping Journal, 2017, 23(2): 280-294.

[44] E Chlebus, B Kuźnicka, T Kurzynowski. Microstructure and mechanical behaviour of Ti-6Al-7Nb alloy produced by selective laser melting. Materials Characterization, 2011, 62(5): 488-495.

[45] B Song, S Dong, P Coddet. Fabrication of NiCr alloy parts by selective laser melting: Columnar microstructure and anisotropic mechanical behavior. Materials \& Design, 2014, 53: 1-7.

[46] K Kempen, E Yasa, L Thijs, et al. Microstructure and mechanical properties of selective laser melted $18 \mathrm{Ni}-300$ steel. Physics Procedia, 2011, 12: 255-263.

[47] H Hill, S Huth, S Weber, et al. Corrosion properties of a plastic mold steel with special focus on the processing route. Materials and Corrosion, 2011, 62(5): 436-443.

[48] A Leon, A Shirizly, E Aghion. Corrosion behavior of AlSi10 Mg alloy produced by additive manufacturing (AM) vs. its counterpart gravity cast alloy. Metals, 2016, 6(7): 148. 
[49] L D Barlow, M D Toit. Effect of austenitizing heat treatment on the microstructure and hardness of martensitic stainless steel AISI 420. Journal of Materials Engineering and Performance, 2012, 21(7): 1327-1336

[50] A N Isfahany, H Saghafian, G Borhani. The effect of heat treatment on mechanical properties and corrosion behavior of AISI420 martensitic stainless steel. Journal of Alloys and Compounds, 2011, 509(9): 3931-3936

[51] I Y Khalfallah, M N Rahoma, J H Abboud, et al. Microstructure and corrosion behavior of austenitic stainless steel treated with laser. Optics \& Laser Technology, 2011, 43(4): 806-813.
[52] O Hakimi, E Aghion, J Goldman. Improved stress corrosion cracking resistance of a novel biodegradable EW62 Mg alloy by rapid solidification, in simulated electrolytes. Materials Science and Engineering: C, 2015, 51: 226-232.

[53] S Wen, S Li, Q Wei, et al. Effect of molten pool boundaries on the mechanical properties of selective laser melting parts. Journal of Materials Processing Technology, 2014, 214(11): 2660-2667.

\section{Submit your manuscript to a SpringerOpen ${ }^{\circ}$ journal and benefit from:}

- Convenient online submission

- Rigorous peer review

- Open access: articles freely available online

- High visibility within the field

- Retaining the copyright to your article

Submit your next manuscript at $\boldsymbol{\nabla}$ springeropen.com 